Nevşehir Bilim ve Teknoloji Dergisi Cilt 3(2) 48-56 2014

DOI: 10.17100/nevbiltek.210932

URL: http://dx.doi.org/10.17100/nevbiltek.210932

\title{
Organik Kirleticilerin Tuzcul Çevrelerde Biyodegredasyonu
}

\author{
Nurnehir Baltacı $^{1,2, *}$, Zehra Nur Yüksekdağ ${ }^{1}$ \\ ${ }^{1}$ Gazi Üniversitesi, Fen Fakültesi, Biyoloji Bölümü, Biyoteknoloji ABD, Teknikokullar, Ankara \\ ${ }^{2}$ Gazi Üniversitesi, Tıp Fakültesi, Tıbbi Mikrobiyoloji ABD, Beşevler, Ankara
}

Özet

Günümüzün en önemli çevresel sorunlarından biri petrol kirleticilerinin sebep oldukları kirliliklerdir. Petrol arama ve çıkarma çalışmaları, tanker ve gemi kazaları, petrol aktarma, depolama çalışmalarında meydana gelen sızıntılar, petrokimya endüstrisi vb. birçok faaliyet petrol kirliliklerinin yoğun bir şekilde yaşanmasına neden olmaktadır. Yapılan çalışmalar, bazı mikroorganizma türlerinin, kirliliğe sebep olan petrol hidrokarbonlarını çeşitli oranlarda parçalayabildiklerini (biyodegredasyon) göstermiştir. Hidrokarbon kirleticilerinin mikroorganizmalar tarafindan biyodegredasyonu tuzcul alanlarda yüksek tuz konsantrasyonları sebebiyle her çeşit mikroorganizma ile yapılamamaktadır. Bu nedenle tuzcul alanlarda meydana gelen kirliliğin giderilmesi için yapılan araştırmalar önem kazanmaktadır. Bu derlemede, çevre biyoteknolojisi açısından önemli olan halofilik mikroorganizmaların petrol hidrokarbonlarını biyodegrede edebilme özellikleri hakkında bilgi verilmiştir.

Anahtar kelimeler: Biyodegredasyon, halofilik bakteri, halofilik arke.

\section{Biodegradation of Organic Pollutants in Saline Enviroments}

\begin{abstract}
One of the most important environmental problems of our days is the pollutions caused by the petroleum pollutants. A number of activities like petroleum exploration and extraction works, tanker and ship accidents, leakages that occur in petroleum transfer and storage works, petrochemical industry, etc. are causing petroleum pollutions to be experienced in an intensive manner. The works carried out have shown that some varieties of microorganisms can disintegrate petroleum hydrocarbons (biodegradation) that are causing pollution in various ratios. The biodegradation of the hydrocarbon pollutants by microorganisms cannot be made by every type of microorganism due to high salt concentrations in saline areas. Due to this reason, the researches that have been carried out in saline areas for remedying the pollution that occur in saline areas are gaining importance. Information has been provided in this compilation on the biodegradation ability properties of petroleum hydrocarbons by the halophylic microorganisms that are important from the point of view of environmental biotechnology.
\end{abstract}

Key Words: Biodegradation, halophilic bacteria, halophilic archaea.

* e-mail: nurnehirgazi@gmail.com 


\section{Giriş}

Dünya nüfusunun hızla artması ile birlikte çoğalan insan faaliyetleri ve teknolojik gelişmeler, çevre sorunlarına neden olmaktadır. Günümüzde yaşanan en önemli çevresel sorunlardan biri de organik kirleticilerden kaynaklanan su, toprak ve hava kirliliğidir. Sanayi teknolojilerinin gelişmesi ve gelişen teknolojilerin günlük hayatımızın bir parçası olması ile petrol ve petrol türevlerinin kullanımı hızlanmıştır. Petrol ve petrol türevi organik maddelerin üretimi, taşınması, depolanması ve kullanımı sırasında kazara sızıntıları ya da bilinçsizce deşarjları, canlı ve çevre sağlığını tehdit eden kirliliklere neden olmaktadır [1]. Çevre kirleticilerinin ortaya çıkmasıyla, kirleticilerin bertarafinda yeni nesil teknolojik uygulamalara ihtiyaç duyulmaktadır. Bu nedenle multidisipliner bir bilim olan Çevre Biyoteknolojisi gelişmiştir. Sanayi, tarım, madencilik, eczacılık vs. kaynaklı kirleticilerin neden oldukları kirliliklerin giderilmesinde, biyokimyasal potansiyeli olan mikroorganizmaları ve bitkileri kullanan Çevre Biyoteknolojisi uygulamaları geliştirilmektedir. Çevresel Biyoteknoloji ilk olarak 19.-20. yüzyıllarda kentsel atık suların arıtılmasıyla başlamıştır [2]. Günümüzde karşımıza çıan çeşitli kirletici etmenlerin, çevrede oluşturdukları kirliliğin giderilmesinde ve atıkların yeniden ham madde olarak kullanılmasında, biyoteknolojik uygulamalara gittikçe artan bir ilgi vardır.

Dünya üzerindeki geniş körfezler, okyanuslar ve suyolları çoktan petrol ürünleri ve zehirli kimyasal atıklarla kontamine olmuş durumdadır. Tahmini olarak 2 milyon tondan fazla ham petrol her yıl denizlere karışmaktadır. Denizlerde kirliliklere sebep olan atıkların yaklaşık yarısı endüstriyel atıklardır. Ayrıca denizlerde, atıkların nehirlere deşarjı yoluyla, nakliyelerden kaynaklanan sızıntılarla ve gemi kazalarıyla, deniz tabanınında olan petrol arama ve çıkarma çalışmarında oluşan sızıntılar ile kontaminasyonlar oluşmaktadır [3,4].

\section{Petrol ve Biyodegredasyon}

Mikroorganizmaların metabolik aktiviteleriyle organik kirleticileri tehlikesiz forma dönüştürmelerine biyodegredasyon denilmektedir. Biyodegredasyonda kirleticiler doğal yollarla, kontamine olmuş bölgeden uzaklaştırılmaktadır [5]. Biyolojik degredasyonun düşük maliyetli olması, organik kirleticilerin doğal ve etkili şekilde gidermesi, pek çok çevre bilimci ve mühendisin ilgi odağı haline gelmesine neden olmuştur [6,7]. Biyodegredasyonda biyolojik olarak parçalanabilen bileşikler, mikroorganizmanın hücre dışı enzimlerine bağlanıp hücre membranından geçerek, hücre içerisine taşınmaktadır. Hücre içerisinde bir seri dönüşüm reaksiyonları ile daha küçük ara ürünlere parçalanma gerçekleşir. Bu reaksiyonlar esnasında enerji açığa çıkmaktadır. Açığa çıkan enerji hücrelerin çoğalmasında, onarılmasında, bileşiklerin hücreye taşınmasında ve hareket etmesinde kullanılmaktadır. Biyolojik parçalanmada, organik bileşikler çoğunlukla $\mathrm{CO}_{2}$ ve $\mathrm{H}_{2} \mathrm{O}$ ’ya dönüşürler [8].

Petrol, çeşitli organik bileşiklerden oluşmaktadır. Petrolde bulunan hidrokarbonlar doygunlar, aromatikler, asfaltenler (fenoller, yağ asitleri, ketonlar, esterler ve porfirinler) ve reçineler (pridinler, quinolinler, karbozoller, sulfoksitler ve amitler) olmak üzere dört grupta incelenmektedir [4]. Rafine yakıtlar, ham petrolün rafinasyon işlemlerinden geçmesi sonucu elde edilmektedir. Yüksek sıcaklıkta yapılan katalitik işlemler gibi bir dizi işlemden geçirilerek, ham petrolden elde edilen benzin arttırılır. Rafine benzinler \%16-25 alifatik, \%35-55 sikloalkan, \%10-20 aromatik hidrokarbonlar ve \%15'den fazla 
yakıt oksijenatları içerirken, aromatik hidrokarbonlar \% 1-2 benzen, toluen, etil benzen ve ksilen (BTEX) içermektedir [9].

Yapılan çalışmalarda petrol hidrokarbonu olan BTEX bileşenlerinin, düşük konsantrasyonlarındaki maruziyetler de bile ciddi merkezi sinir sistemi rahatsızlıklarına yol açabileceği rapor edilmektedir [10,11]. Bu nedenle BTEX bileşenleri, ABD Çevre Koruma Birimi (United States Enviromental Protection Agency) tarafından, yüksek kararlılıkta, suda çözünebilen ve insan karsinojeni olarak listelenmiştir [11]. Hidrokarbonların mikrobiyal parçalanmadaki duyarlılıkları genellikle şöyle derecelendirilmektedir; düz alkanlar $>$ dallanmış alkanlar $>$ küçük aromatikler $>$ halkasal alkenler [12]. Düşük moleküler ağırlıktaki hidrokarbonlar, degredasyon metabolizmasına sahip mikroorganizmalar tarafından kolaylıkla parçalansalar da, yüksek moleküler ağırlıktaki polisiklik aromatik hidrokarbonlar (PAH) gibi bazı bileşenler tamamen parçalanamamaktadır [13].

Mikroorganizmalarla BTEX bileşenlerinin parçalandığı, ilk olarak 1900’lü yılların başında Gibson ve Subramanian tarafından rapor edilmiştir [14]. Daha sonrasında, hangi mikroorganizmaların hangi şartlar altında BTEX degredasyonunu gerçekleştirebildiği hakkında çalışmalar yapılmaya başlanmıştır. Çeşitli çevrelerde yaşayan organizmaların, aerobik [14,15] ve anaerobik [16-18], şartlar altında BTEX parçalayabildikleri gösterilmiştir. Bu özellikleri psikrofilik $[5,19]$ ve termofilik şartlarda da $[17,20]$ gösterdikleri gözlenmiştir. BTEX degredasyonunun tuzcul [21], asidofilik, alkalifilik ve barofilik şartlarda gerçekleştiğini kanıtlayan çok az veri bulunmaktadır [22].

\section{Halofilik Mikroorganizmalarm Organik Kirleticileri Biyodegredasyonu}

Halofilik organizmaların metabolik çeşitliliği, fenotipik çeşitlilikleri kadar gelişmiştir. Çoğu mikrobiyal işlem düşük tuz konsantrasyonlarından yüksek tuz konsantrasyonlarına değişik aralıklarda meydana gelebilir. Mikroorganizmanın birincil ya da ikincil mekanizması, ortam şartlarına ve organizmanın gereksinimlerine göre şekillenmektedir. Biyodegredasyon ve biyoremidasyon uygulamalarında kullanılacak olan organizmalar bu özelliklere dikkat edilerek seçilmektedir. Yani tuzcul bir ortamdaki organik kirletici kontaminasyonlarının biyolojik olarak giderilmesinde, halofilik ya da halotolerant olmayan bir organizma yüksek tuzluluğun getirdiği osmotik strese, su ve besin azlığına cevap oluşturamayacağı için biyodegredasyon ve biyoremidasyon uygulamalarında kullanılamamaktadır. Bu gibi habitatlarda organik kirleticileri parçalama metabolizmasına sahip halofilik ve halotolerant organizmalar kullanılmaktadır [5,23].

Endüstriyel işlemlerin sonucu oluşan atık sular, petrol çalışmalarında oluşan atıklar, çeşitli nedenlerden kaynaklanan aromatik bileşenlerin doğaya sızıntıları denizel ekosistemler gibi tuzcul alanları olumsuz etkilemektedir [24]. Denizel ekosistemlerde besin ve fosfor azlığı, tuzluluk oranları gibi sebepler degredasyon metabolizması olan mikroorganizmaların gelişimini kısıtlayıcı faktörlerdir [4]. Buna rağmen sürekli olarak kontaminasyona maruz kalan bölgelerde degredasyon metabolizmasına sahip organizmaların kirletici unsurları karbon ve enerji kaynağı olarak kullanma yetisinin arttığı gözlenmiştir $[22,25]$.

Bakterilerin çok yüksek tuzlulukta bile petrol hidrokarbonlarını parçalayabildikleri gösterilmiştir. Tunus'da ki açık deniz petrol sahasında yapılan çalışmada Halomonas sp. C2SS100 suşunun ham petrolü parçalayabildiği tespit edilmiştir [26]. Arkeal, Halobacterium ve Halococcus cinslerine ait bazı türlerinde 
petrol hidrokarbonlarını parçalayabildiği bildirilmiştir [27]. Tuzcul çevrelerdeki organizmalardan Marinobacter hydrocarbonoclasticus'un eikozan [28], Halomonas elongat'nn 2,4-diklorofenoksatik asit [29] ve Alteromonas'a ait bazı suşların organofosfor bileşenlerini [30] içeren pek çok bileşiği parçalayabildiği bilinmektedir. Halofilik Methylomicrobium sp. \% 2-6 tuzlulukta trikloroetileni okside edebilmektedir ve deniz kirliliklerinin giderilmesinde kullanılabileceği ifade edilmektedir [22,31]. Aromatik bileşiklerle kontamine olmuş tuzcul çevrelerde halofilik bakterilerin katabolik rolü Garcia ve arkadaşları tarafından araştırılmış ve Halomonas sp.'nin içerisinde fenolik atık bulunan tuzlu suların temizlenmesinde kullanılabileceği bildirilmiştir [32]. Lefebvre ve arkadaşları da deri işleme atık suyunun biyolojik olarak temizlenmesi için halofilik mikroorganizmaları önermişlerdir [33].

Yüksek tuzluluktaki çeşitli bölgelerden izole edilen Haloferax volcanii, Halococcus morrhuae, Halobacterium salinarum ve Haloarcula marismortui arke türleri p-hidroksibenzoik asiti (pHBA) biyodegrede edebilmektedir [34]. Halomonas cinsine ait olan $H$. salina ve $H$. halophila benzoik asit, pHBA, fenol, ferulik asit ve p-aminosalisilik asit, salisilikasit fenilasetik asit gibi birçok organik kirleticiyi parçalayabilmektedir [35]. Ekstrem halofilik arke olan Haloterrigena sp. H13 suşu sahip olduğu metabolik ve genomik özelliklerinden dolayı 1,2-dikloroetan, naftalin, $\gamma$-hekzaklorahekzan, 1-/2metilnaftalin ve benzoat degredasyonunda kullanılabileceği bildirilmektedir [36]. Uyuni (Bolivya), Şili ve Kabo Rojo (Porto Riko), Sabkhas (Suudi Arabistan) ve Ölü Deniz (İsrail)'den izole edilen 10 Haloarchaea sp. suşu ile yapılan çalışmada, izole edilen suşların \% $20 \mathrm{NaCl}$ konsantrasyonunda benzoik asit, pHBA ve salisilik asit (her birinden $1,5 \mathrm{mM}$ ) ile polisiklik aromatik hidrokarbonlar, naftalin, anthracen, fenantheren, piren ve benzo[a]anthrasen (her biri 0,3 $\mathrm{mM}$ ) maddelerinden oluşan karışımı degrede edebildiği gösterilmiştir [37]. Ayrıca Halobacterium salinarium'un izopropil alkol'ü parçalayan enzimlere sahip olduğu rapor edilmektedir [38]. Halorubrum sp. ve H. ezzemoulense'in \% 20 (w/v) NaCl varlığında, $p$-hidroksibenzoik asit, naftalin, fenantren ve pireni karbon kaynağı olarak kullanabildiği gösterilmiştir [39].

Gao ve arkadaşları Güney Çin Denizi’nden izole ettikleri Marinobacter nanhaiticus türünün naftalin, fenantren ve antraseni degrede edebildiğini rapor etmiştir [40]. Ilımlı halofilik bakteri olan Martelella sp. AD-3 suşunun \% 0,1 ile 15 arasında değişen tuzluluk ve 6-10 arası değişen pH'da polisiklik aromatik hidrokarbonlarını yüksek kapasitede parçalayabildiği bildirilmiştir [41,42]. İran' da yapılan bir çalışmada ise rafineri çevresindeki halofilik topraklardan izole edilen Halomonas sp. pH 2-2 suşunun, \% $18 \mathrm{NaCl}$ konsantrasyonunda fenolu parçaladığ belirlenmiştir [7]. Başka bir çalışmada ise benzer olarak, kimyasal atık içeren kıyı sedimentlerinden izole edilen Halomonas sp. suşunun optimal $30^{\circ}$ C'de $\mathrm{pH}$ 6,5-8,5 arasında ve \% 10-20 (v/v) tuz konsantrasyonunda, farklı azo boyalarını 24 saat içinde \%90'ın üzerinde biyolojik olarak uzaklaştırdığını göstermişlerdir [43].

BTX bileşiklerini degrede edebilecek metabolizma ve enzimlere sahip olan mikroorganizmalar, bu bileşenleri daha kolay kullanabilecekleri çeşitli bileşiklere dönüştürürler. Tuzcul alanlarda oluşan BTX kontaminasyonlarının giderilmesi için halofilik ya da halotolerant mikroorganizma faaliyetlerine ihtiyaç duyulmaktadır [44]. Özellikle açık deniz petrol arama sahaları, gemi kazaları, tanker sızıntıları, kentsel ve endüstriyel atıkların denize kontrolsüz deşarjı gibi sebeplerle petrol ve petrol hidrokarbonları (BTX) ile kontaminasyona en çok maruz kalan deniz sistemlerinde bu kirleticileri elemine edecek, ortam şartlarından etkilenmeyecek mikroorganizmaların belirlenmesi önem taşımaktadır [5,45]. 
Monosiklik aromatik hidrokarbon olan BTX bileşenlerinin degredasyonu ile ilgili yapılan bir çalışmada yüksek tuz konsantrasyonlarında Marinobacter hydrocarbonoclasticus ve Marinobacter sp.'nin benzen, toluen ve ksilen üzerinde gelişebildiği, Marinobacter vinifirmus'un tolueni tek karbon ve enerji kaynağı olarak kullanabildiği bildirilmiştir [46]. Ekstrem halofilik bakteri olan Arhodomonas sp. seminole suşu ve Arhodomonas sp. rozel suşunun benzen ve tolueni yüksek tuzlulukta (0,5-4 M NaCl) karbon ve enerji kaynağı olarak kullandığı rapor edilmektedir [23]. Yine Doğu Çin Deniz’inde yapılan bir çalışmada Marinobacter, Prolixibacter, Balneola, Zunongwangia, Halobacillus cinsleri kullanılarak BTX bileşenlerinden, $120 \mathrm{mg} / \mathrm{L}$ tolueni 5 günde degrede edildikleri bildirilmiştir [47]. Chennai gemi limanından (Hindistan) alınan deniz suyundan izole edilen halotolerant Ochrobacterum sp., Enterobacter cloacea ve Stenotrophomonas maltophilia bakteriler ile yapılan çalışmada, 60 g/L $\mathrm{NaCl}$ konsantrasyonunda 4 gün içerisinde \% 74 oranında polisiklik aromatik bileşenleri parçalayabildiği gösterilmiştir [48].

Halofilik arkelerin BTX bileşenlerini parçalaması hakkında çok kısıtlı bilgi bulunmaktadır. Bir çalışmada, Kandla (Hindistan) hipersalin bölgesinden izole edilen ve \% $25 \mathrm{NaCl}$ konsantrasyonunda gelişen Halobacterium sp. SP1, Haloarcula sp. SP2 ve Haloferax sp. SP1 arkeleri ile organik çözücülere (toluen, ksilen, n-dekan, n-dodekan, n-undekan) toleransı araştırılmıştır. Çalışma sonucunda ise Halobacterium sp. SP1'in Haloarcula sp. SP2 ve Haloferax sp. SP1'e göre organik çözücülere daha toleranslı olduğu bulunmuştur [49].

\section{Sonuç}

Günlük hayatımızdan endüstriyel alanlara kadar çeşitli amaçlarla kullanılan, su ve karasal ekosistemlerde petrol kirleticileri büyük risk oluşturmaktadır. Petrol kirleticilerinin giderilmesinde bugüne kadar pek çok yöntem geliştirilmiştir. Ancak kullanılan diğer fiziksel ve kimyasal yöntemlerin, kirliliğin giderilmesinde yeterli olmamaları, doğaya dost olmamaları, pahalı ve zor uygulanabilir olmaları gibi nedenlerden dolayı sıklıkla uygulanamamaktadır. Kontamine alanların iyileştirilmesinde biyodegredasyon ve biyoremidasyon yöntemleri düşük maliyet ve çok yüksek oranlarda mineralizasyonu sağladığı için gün geçtikçe önem kazanan ümit verici bir teknoloji olarak karşımıza çıkmaktadır. Her ne kadar farklı çevrelerde çok yüksek oranlarda petrol hidrokarbonlarının neden oldukları kirlilikleri biyodegrade edebildiği bilinen çok sayıda farklı mikroorganizma bilinmesine rağmen, tuzcul ve çok tuzcul çevreler için veriler oldukça kısıtlıdır. Tuzlu çevrelerdeki yüksek tuz konsantrasyonu, besin azlığı gibi sebepler yüksek kapasitede biyodegredasyon yeteneğine sahip mikroorganizmaların yaşamasına izin vermemektedir. Dolayısıyla bu tip çevrelerde meydana gelen kirliliklerin giderilmesinde halofilik ve halotolerant mikroorganizmaların kullanılması gerekmektedir. $\mathrm{Bu}$ nedenle tuzcul ve çok tuzcul çevrelerdeki petrol hidrokarbonu kirliliklerinin biyodegredasyonunda kullanılabilecek mikroorganizmaların belirlenmesi için daha çok çalışma yapılması gerekmektedir.

\section{Bilgi veTeşekkür}

Bu çalışma, G. Ü. Fen Bilimleri Enstitüsü Biyoloji Anabilim Dalı’nda Doç. Dr. Zehra Nur YÜKSEKDAĞ danışmanlığında Nurnehir BALTACI tarafindan yapılan 'Petrol Hidrokarbonu 
Kirleticilerinin Halofilik Bakteri ve Halofilik Archaea Türleri Kullanılarak Biyodegredasyonu' adlı yüksek lisans tezinin kaynak araştırmasından özetlenmiştir.

\section{Kaynaklar}

[1] Harayama S., Kishira H., Kasai Y., Shutsubo K., "Petroleum biodegradation in marine environments” Journal of Molecular Microbiology and Biotechnology, 1(1), 63-70, 1999.

[2] Hartmann L., "Historical development of wastewater treatment processes, in biotechnology: environmental processes.” In ( Ed. J Winter) Wileyvch Weinheim, 1(1), 5-16, 1999.

[3] Leung K., T., Nandakumar K., Sreekumari K., Lee H., Trevors T., "Biodegradation and bioremidation of organic pollutants in soil” 2nd end. Modern Soil Microbiology CRC Press, Boca Raton, Florida, 522-549, 2006.

[4] Das N., Chandran P., "Microbial degredation of petroleum hydrocarbon contaminantas: An Overview.” Biotechnology Research International, 2011, 1-13, 2010.

[5] Margesin R., Schinner F., "Biodegradation and bioremediation of hydrocarbons in extreme environments.” Applied Microbiology and Biotechnology, 56, 650-663, 2001.

[6] Park M., R., Kim D., J., Choi J.,W., Lim D., S., "Influence of immobilization of bacterial cells and $\mathrm{TiO}_{2}$ on phenol degradation.” Water, Air and Soil Pollution, 224, 1-9, 2013.

[7] Haddadi A., Shavandi M., "Biodegradation of phenol in hypersaline conditions by Halomonas sp. strain PH2-2 isolated from saline soil." International Biodeterioration and Biodegradradation, 85, 29-34, 2013.

[8] Roberts E., R., “Remediation of petroleum contamined soils.” Lewis Publishers, New York, 139249, 1992.

[9] Azetsu S., "BTEX degradation at high salinity in rozel point.” Oklahoma State University, Master Thesis, USA, 15-35, 2009.

[10] Bianchin J., N., Nardini G., Merib J., Dias A., N., Martendal E., Carasek E.,. “Simultaneous determination of polycyclic aromatic hydrocarbons and benzene, toluene, ethylbenzene and xylene in water samples using a new sampling strategy combining different extraction modes and temperatures in a single extraction solid-phase microextraction-gas chromatography-mass spectrometry procedure.” Journal of Chromatography A, 1233, 22-29, 2012.

[11] Fernandes A., N., Gouveida C., D., Grassi M., T., da Crespo S., Giovanela M., "Determination of Monoaromatic Hydrocarbons (BTEX) in Surface Waters from a Brazilian Subtropical Hydrographic Basin.” Bulletin of Environmental Contamination and Toxicology, 92, 445-459 2014.

[12] Ulrici W., "Contaminant soil areas, different countries and contaminant monitoring of contaminants," in Environmental Process II. In Edith by Rehm H., J., Reed G., Soil Decontamination Biotechnology 11, 5-42, 2000.

[13] Atlas R., Bragg J., "Bioremediation of marine oil spills: when and when not-the Exxon Valdez experience.” Microbial Biotechnology, 2(2), 213-221, 2009.

[14] Gibson D., T., Subramania V., "Microbial degradation of aromatic hydrocarbons.” In Edith.by Gibson D., T., Microbial degradation of organic compounds, Marcel Dekker, Inc., New York, 181-252, 1984. 
[15] Deeb R., A., Alvarez-Cohen L., “Temperature effects and substrate interactions during the aerobic biotransformation of BTEX mixtures by toluene-enriched consortia and Rhodocossus rhodochrous.” Biotechnology and Bioengineering, 62, 526-536, 1999.

[16] Lovley D., R., Woodward J., C., Chapelle F., H., "Rapid anaerobic benzene oxidation with a variety of chelated Fe (III) forms.” Applied Environmental Microbiolology, 62, 288- 291, 1996.

[17] Chen C., I., Taylor R., T., “Themophilic biodegradation of BTEX by two consortia of anaerobic bacteria.” Applied Microbiology Biotechnology, 48, 121-128, 1997.

[18] Gieg L., M., Kolhatkar R., V., McInerney M., J., Tanner R., S., Harris S., H., Jr., Sublette K., L., Suflita J., M.,. "Intrinsic bioremediation of petroleum hydrocarbons in a gascondensatecontaminated aquifer.” Environmental Science and Technology, 33, 2550-2560, 1999.

[19] Braddock J., F., McCarthy K., A., "Hydrologic and microbiological factors affecting persistence and migration of petroleum hydrocarbons spilled in a continuous-permafrost region.” Environmental Science and Technology, 30, 2626-2633, 1996.

[20] Chen C., I., Taylor R., T.,. "Thermophilic biodegradation of BTEX by two Thermus species.” Biotechnology and Bioengineering 48, 614-624, 1995.

[21] Brusa T., Borin S., Ferrari F., Sorlini C., Corselli C., Daffonchio D., “Aromatic hydrocarbon degradation patterns and catechol 2, 3-dioxygenase genes in microbial cultures from deep anoxic hypersaline lakes in the eastern Mediterranean Sea.” Microbiological Research 156, 49-57, 2001.

[22] Nicholson C., A., "Biodegredasyon of petroleum hydrocarbons by halophilic and halotolerant microorganisms.” Oklahoma State University, Master Thesis, USA, 3-40,2005.

[23] Dalvi S., Azetsu S., Patrauchan M., A., Aktaş D., F., Fathepure B., Z., "Proteogenomic elucidation of the initial steps in the benzene degradation pathway of a novel halophile, Arhodomonas sp. strain Rozel, isolated from a hypersaline enviroment.” Applied Environmental Microbiology 78, 7309-7316, 2012.

[24] Malik Z., A., Ahmed S., "Degradation of petroleum hydrocarbons by oil field isolated bacterial consortium.” African Journal of Biotechnology, 11(3),650- 658, 2012.

[25] Bragg J., R., Prince R., C., Harner E., J., Atlas R., M., “Effectiveness of bioremediation for the Exxon Valdez oil spill.” Nature, 368,413-418,1994.

[26] Mnif S., Chamkha M., Sayadi S., "Isolation and characterization of Halomonas sp. strain C2SS100, a hydrocarbon-degrading bacterium under hypersaline conditions.” Journal of Applied Microbiology, 107, 785-794, 2009.

[27] Al-Mailem D., M., Sorkhoh N., A., Marafie M., Al-Awadhi H., Eliyas M., Radwan S., S.,. “Oil phytoremediation potential of hypersaline coasts of the Arabian Gulf using rhizosphere technology.” Bioresource Technology, 101, 5786-5792, 2010.

[28] Fernandez-Linares L., Acquaviva M., Betrand J., C., Gauthier M., "Effect of sodium chloride concentration on growth and degradation of eicosane by the marine halotolerant bacterium Marinobacter hydrocarbonoclasticus.” Systematic and Applied Microbiology, 19, 113-121, 1996.

[29] Maltseva O., McGowan C., Fulthorpe R., Oriel P., "Degradation of 2,4 dichlorophenoxyacetic acid by haloalkaliphilic bacteri.” Microbiology, 142,1115-1122, 1996. 
[30] DeFrank J., Cheng T., C., "Purification and properties of an organophosphorus acid anhydrase from a halophilic bacterial isolate.” Journal of Bacteriology, 173, 1938-1943, 1991.

[31] Fuse H., “Oxidation of organic compounds by bacteria.” Japanese Patent, JP10128385, May $19,1998$.

[32] Garcia M., T., Ventosa A., Mellado E., “Catabolic versatility of aromatik compound- degrading halophilic bacteria.” FEMS Mirobiology Ecology, 54, 97-109, 2005.

[33] Lefebvre O., Vasudevan N., Moletta R., "Halophilic biological treatment of tannery soak liquor in a sequencing batch reaktor.” Water Research, 39, 1471-1480, 2005.

[34] Cuadros-Orellana S., Pohlschröder M., Durrant L., R., "Isolation and characterization of halophilic archaea able to grow in aromatic compounds.” International Biodeterioration and Biodegradation, 57, 151-154, 2006.

[35] Garcia M., T., Mellado E., Ostos J., C., Ventosa A., “Halomonas organivorans sp. nov., a moderate halophile able to degrade aromatic compounds.” International Journal of Systematic and Evolutionary Microbiology, 54,1723-1728, 2004.

[36] Ding J., Y., Lai M., C., “The biotechnological potential of the extreme halophilic archaea Haloterrigena sp. H13 in xenobiotic metabolism using a comparative genomics approach.” Environmental Technology,31, 905-914, 2010.

[37] Bonfa M., R., L., Grossman M., J., Mellado E., Durrant L., R., “Biodegradation of aromatic hydrocarbons by haloarchaea and their use for the reduction of the chemical oxygen demand of hypersaline petroleum produced water.” Chemosphere, 84, 1671-1676, 2011.

[38] Ha D., J., Joo W., A., Han G., Y., Kim C., W., "Proteome analysis of Halobacterium salinarum and characterization of proteins related to the degradation of isopropyl alcohol”. Biochimica et Biophysica Acta, 1774,44-50, 2007.

[39] Erdoğmuş S., F., Mutlu B., Korcan S., E., Güven K., Konuk M., “Aromatic hydrocarbon degradation by halophilic archaea isolated from Çamaltı Saltern, Turkey.” Water, Air and Soil Pollution, 224(3),1-9, 2013.

[40] Gao W., Cui Z., Li Q., Xu G., Jia X., Zheng L., “Marinobacter nanhaiticus sp. nov., polycyclic aromatic hydrocarbon-degrading bacterium isolated from the sediment of the South China Sea.” Antonie Van Leeuwenhoek, 103, 485-491, 2013.

[41] Cui C., Z., Feng T., C., Yu Y., Q., Dong F., Yang X., M., Feng Y., Y., Liu Y., D., Lin H., P., "Isolation, characterization of an anthracene degrading bacterium Martelella sp. AD-3 and cloning of dioxygenase gene.” Environmental Science (Huanjing Kexue), 33, 4062-4068, 2012.

[42] Cui C., Li P., Liu G., Tang H., Lin K., Luo Q., Liu S., Xu P., Liu Y., “Genome sequence of Martelella sp. strain AD-3, a moderately halophilic polycyclic aromatic hydrocarbon-degrading bacterium.” Genome Announcements, 2(1), e01189-13, 2014.

[43] Guo J., Zhou J., Wang D., Yang J., Li Z., “The new incorporation bio-treatment technology of bromoamine acid and azo dyes wastewaters under high-salt conditions.” Biodegradation, 19, 9398, 2008.

[44] Nicholson C., A., Fathepure B., Z., "Biodegradation of benzene by halophilic and halotolerant bacteria under aerobic conditions.” Applied Environmental Microbiology, 70(2), 222-225 2004. 
[45] Veenagayathri K., Vasudevan N., "Effect of $\mathrm{pH}$, nitrogene sources and salts on the degradation of phenol by the bacterial consortium under saline conditions.” International Journal of Biotechnology and Biochemistry, 6(5), 783-791, 2010.

[46] Berlendis S., Cayol J., L., Verhé F., Sophie L., Tholozan J., L., Ollivier B., Auria R., "First evidence of aerobic biodegradation of BTEX compounds by pure cultures of Marinobacter." Applied Biochemistry and Biotechnology, 160 (7), 1992-1999, 2010.

[47] Li H., Zhang Q., Wang X., L., Ma X., Y., Lin K., F., Liu Y., D., Gu J., D., Lu S., G., Shi L., Lu Q., Shen T., T., "Biodegradation of benzen homologues in contaminated sediment of the East China Sea.” Bioresour Technology, 124, 129-136, 2012.

[48] Arulazhagan P., Vasudevan N., Yeom I., T., "Biodegradation of polycyclic aromatic hydrocarbon by a halotolerant bacterial consortium isolated from marine environment." International Journal of Environmental Science and Technology, 7(4), 839-852, 2010.

[49] Akolkar A., V., Deshpande G., M., Ravel K., N., Durai D., Nerurkar A., S., Desai A., J., “Organic solvent tolerance of Halobacterium sp. SP1(1) and its extracellular protease.” Journal of Basic Microbiology, 48, 421-425, 2008. 